\title{
DSR Routing Decisions for Mobile Ad Hoc Networks using Fuzzy Inference System
}

\author{
Pankaj Sharma ${ }^{1}$, Shruti Kohli ${ }^{2}$, Ashok Kumar Sinha ${ }^{3}$ \\ ${ }^{1}$ Department of Information Technology, \\ ABES Engineering college, Ghaziabad, UP, India \\ ${ }^{1}$ sharma1pk@gmail.com \\ ${ }^{2}$ Department of Computer Science \& Engineering,BITEC,Noida,UP,India \\ ${ }^{2}$ shruti@bitmesra.ac.in \\ ${ }^{3}$ Department of Information Technology, \\ ABES Engineering college, Ghaziabad, UP, India \\ 3 aksinhadabes.ac, in
}

\begin{abstract}
Mobile ad-hoc network technology has gained popularity in recent years by researchers on account of its flexibility, low cost and ease of deployment. The objective of this paper is to model the behavior of MANET for DSR protocol by considering some prominent routing metrics. These metrics ( packet delivery fraction, normalized routing load, average end- to- end delay etc.) have been generated by Network Simulator NS 2.34 tools and the node movement has been generated using Bonmotion 1.4.The MANET behavior for DSR protocol is hypothesized to be dependent on fuzzy variables like node density, pause time, number of packets transferred, and the number of connection. In this paper the behavior of MANET is modeled using Fuzzy Inference System for DSR (Dynamic Source Routing) protocol, Fuzzy Inference System offers a natural way of representing and reasoning the problems with uncertainty and imprecision. Fuzzy logic is found to be a suitable way in the mobile ad hoc network routing decision. A Fuzzy inference system is implemented on MATLAB 7.0 and the model is found to be satisfactory with the fuzzy input metrics and de fuzzified output metrics .
\end{abstract}

\section{Keywords}

Ad hoc networks, Routing metrics, DSR, Fuzzy Logic, FIS Editor

\section{INTRODUCTION}

In Mobile Ad Hoc Network (MANET), A number of routing protocols have been developed and proposed [1,2], that will help in route discovery and maintenance mechanisms for the mobile node to communicate with other nodes in MANET. The objective of all these protocols is to find the most reliable and feasible path. Since last few years, the research community has developed many routing protocols and submitted in the form of drafts to the group of Internet Engineering and Task Force Mobile Ad-hoc Networking (MANET) [7]. According to them the good protocols are the Optimized Link State Routing (OLSR), Zone Based Routing Protocol(ZRP),Temporally-Ordered Routing

Sundarapandian et al. (Eds): CoNeCo,WiMo, NLP, CRYPSIS, ICAIT, ICDIP, ITCSE, CS \& IT 07, pp. 31-36, 2012. (C) CS \& IT-CSCP 2012

DOI : $10.5121 /$ csit.2012.2404 
Algorithm (TORA), the Ad-Hoc On demand Distance Vector (AODV), the DestinationSequenced Distance Vector (DSDV), the Dynamic Source Routing (DSR) and many more. Here is the brief overview of these protocols.

Many research works have been compared for the different ad hoc routing protocols (OLSR, ZRP, TORA, DSDV, DSR, AODV etc. Johansson, et. al. [3] ) under varying network scenarios. Packet Delivery Ratio (PDR) fraction, Normalized Routing Load and Average end-to-end delay are some prominent metrics used in the comparisons. Throughput and delay of the protocols Perkins,et. al. [4], focused on only comparing the two on-demand routing protocols i.e. DSR and AODV. Yang Cheng Hung, et. al. [5], focused on OLSR protocol compares only Node density versus speed.

Thomas Staub, et. al. [6], focused on DSR and DSDV and find out that they did not supply any valid results in the hybrid situation.

Similarly there are so many research works which have shown a number of comparisons on various routing protocols, analyze the performance of various protocols, there is still no such model or approach which can provide help in MANET area to compute the behavior of protocols using the formula or function, with the help of proposed model in this paper, DSR is the right protocol which shows satisfactory outcomes in most of the Mobile ad hoc network challenges.

All these research works do not provide the methodology to find the sensitivity of performance metrics of MANET with respect to the input metrics. In this paper this issue has been resolved successfully. A lot of research have been done in MANET area, but still there is a gap to overcome the real environment challenges. The proposed model proposed in this paper will be able to shape out the behavior of MANET by using DSR protocol.

\section{TOOLS \& METHODOLOGY}

In this paper we have used various tools such as network simulator version 2.34 (NS2.34) for getting the simulation results by writing and running the TCL script, applying the parameters in Table1,[7] in addition we have taken the help of traffic generation tool such as cbrgen.tcl and mobile movement scenario generation tool such as Bonmotion 1.4, after getting the results .Finally we have used the Fuzzy Inference System tool for testing the behavior of the scenario described in Table 1.

Table 1. SIMULATION PARAMETER

\begin{tabular}{|l|l|}
\hline \multicolumn{2}{|c|}{ Simulation Parameters } \\
\hline Routing Protocol & DSR \\
\hline Mobility Model & RPGM \\
\hline Simulation Time & 100 \\
\hline Number of Nodes & $\begin{array}{l}10,20,30,40,50,60,70,80,90,100,110,120,130,140,150 \\
160,170\end{array}$ \\
\hline
\end{tabular}




\begin{tabular}{|l|l|}
\hline Simulation Area & $\mathrm{x}=800 \mathrm{~m}, \mathrm{y}=800 \mathrm{~m}$ \\
\hline Speed & $\begin{array}{l}\mathrm{l}=0.0 \mathrm{~m} / \mathrm{s}, \mathrm{h}=(5,10,15,20,25,30,35,40,45,50,55,60,65, \\
70,75,80,85) \mathrm{m} / \mathrm{s}\end{array}$ \\
\hline Pause Time & $3,5,7,9,11,13,15,17,19,21,23,25,27,29,31,33,35$ \\
\hline Traffic Type & $\mathrm{CBR}$ \\
\hline Packet Size & 512 bytes \\
\hline Rate & $\begin{array}{l}(5,10,15,20,25,30,35,40,45,50,55,60,65,70,75,80,85) \\
\text { packets/sec }\end{array}$ \\
\hline $\begin{array}{l}\text { Number of } \\
\text { Connections }\end{array}$ & $10,15,20,25,30,35,40,45,50,55,60,65,70,75,80,85,90$ \\
\hline Seed & 1.0 \\
\hline
\end{tabular}

\section{FUZZY ENGINE}

A fuzzy engine, as per Figure 1, is typified by the inference system that includes the system rule base, input membership functions that fuzzify the input variables and the output variable. Fuzzification is a procedure where crisp input values are represented in terms of the membership function, of the fuzzy sets. The fuzzy logic controller triangular membership functions are defined over the range of the fuzzy input values and linguistically describe the variable's universe of discourse as shown in Figure 2. Following the fuzzification process the inference engine determines the fuzzy output using fuzzy rules that are in the form of if then rules. Defuzzification is then used to translate the fuzzy output to a crisp value.

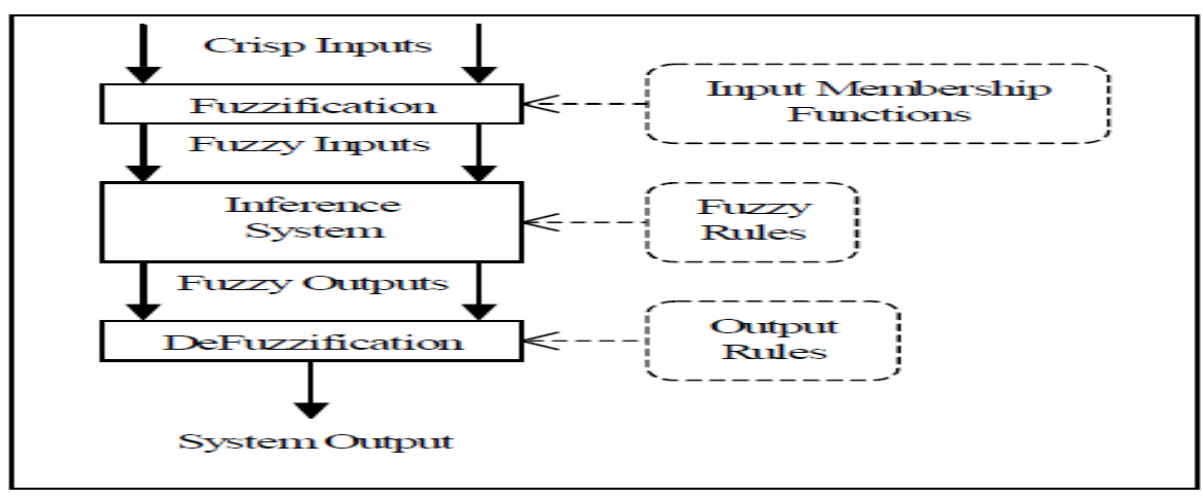

Figure 1. Fuzzy Engine

To compute the output of this FIS given the inputs, one must go through six steps:

1. Determining a set of fuzzy rules

2. Fuzzifying the inputs using the input membership functions, 
3. Combining the fuzzified inputs according to the fuzzy rules to establish a rule strength,

4. Finding the consequence of the rule by combining the rule strength and the output membership function,

5. Combining the consequences to get an output distribution, and

6. Defuzzifying the output distribution for computing the crisp output.

The Figure 2 shows the description of this process.

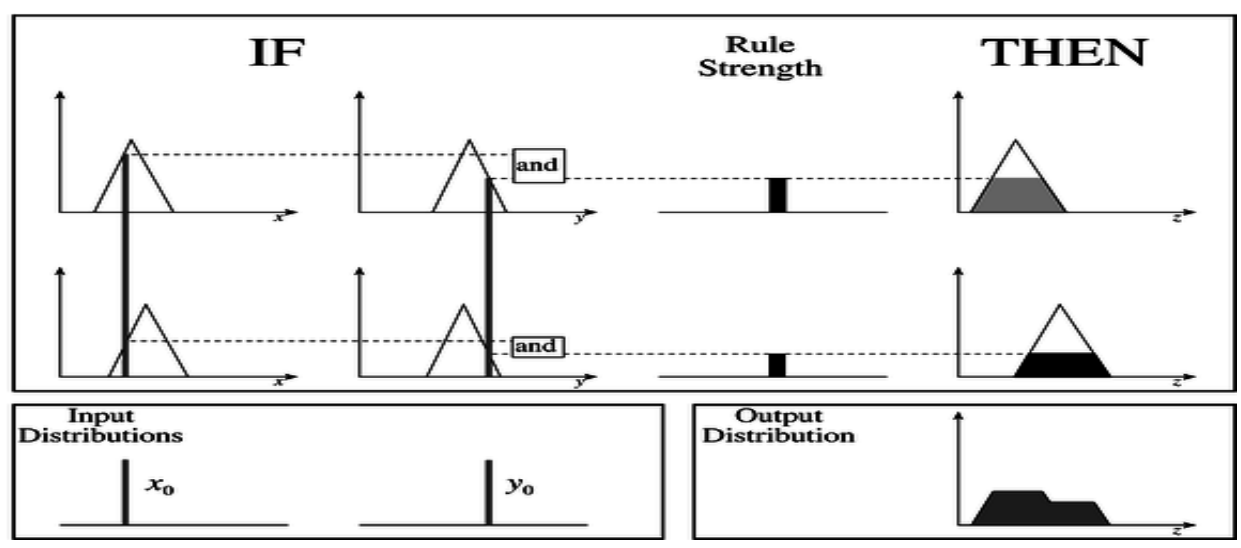

Figure 2. A two input, two rule Mamdani FIS with crisp inputs

\section{FUZZY INFERENCE SYSTEM FOR DSR}

For implementation of the proposed model We have taken some results with the help of network simulator and consider those results as sample input and used these samples in FIS Editor toolbox supported by MATLAB 7.0, and tuned out the DSR , applying the fuzzy logic with the help of Fuzzy inference System and found that in which practical situations the DSR protocol performs poor, satisfactory and acceptable. A fuzzy inference system (FIS) is a system that uses fuzzy set theory to map inputs (node density, pause time, node mobility number of packets transferred, and the number of connection) to outputs (Packet Delivery Fraction, Normalized Routing Load and Normalized MAC Load) in the case of fuzzy classification). In this paper the Mamdani FIS is implemented for tuning the behavior of DSR.

A fuzzy inference system (FIS) is a system that uses fuzzy set theory to map inputs like Node Density(ND), Pause Time(PT), Node Mobility(NM), Number of Packets transferred(NP), and the Number of Connection(NC) to outputs Packet Delivery Fraction(PDF), Normalized Routing $\operatorname{Load}(N R L)$ and Normalized MAC Load(NML) in the case of fuzzy classification . In this paper the Mamdani FIS is taken for tuning DSR. The proposed Inference System is given in Figure. 3, Combining the fuzzified inputs according to the fuzzy rules which are described in Figure. 4 to establish a rule strength and the sample crisp output is shown in Figure 5. 


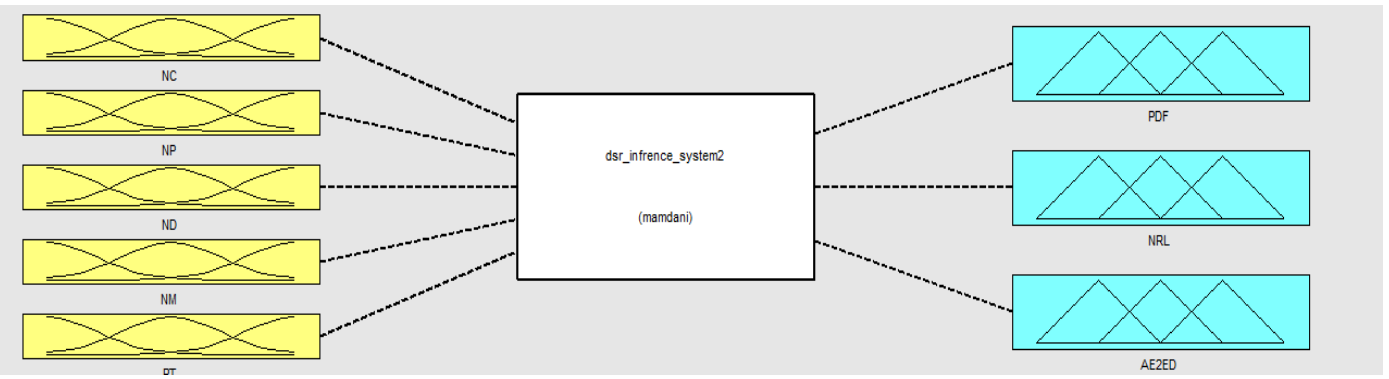

Figure 3. Proposed Fuzzy Inference System for DSR

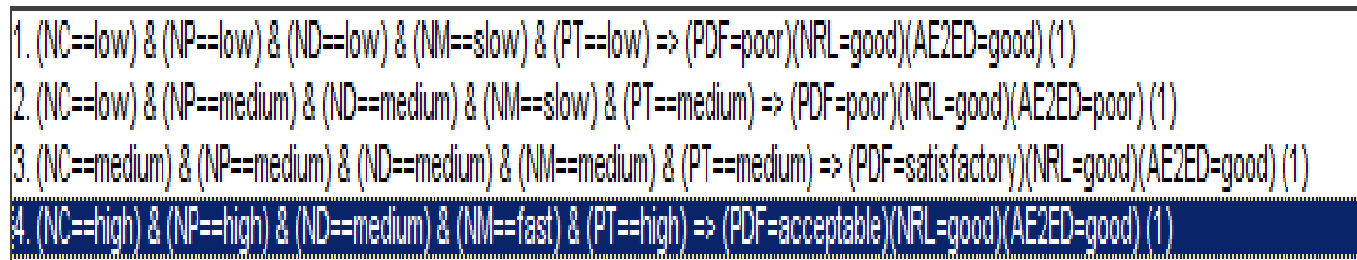

Figure 4. Fuzzy Rules for Fuzzyfying the given inputs

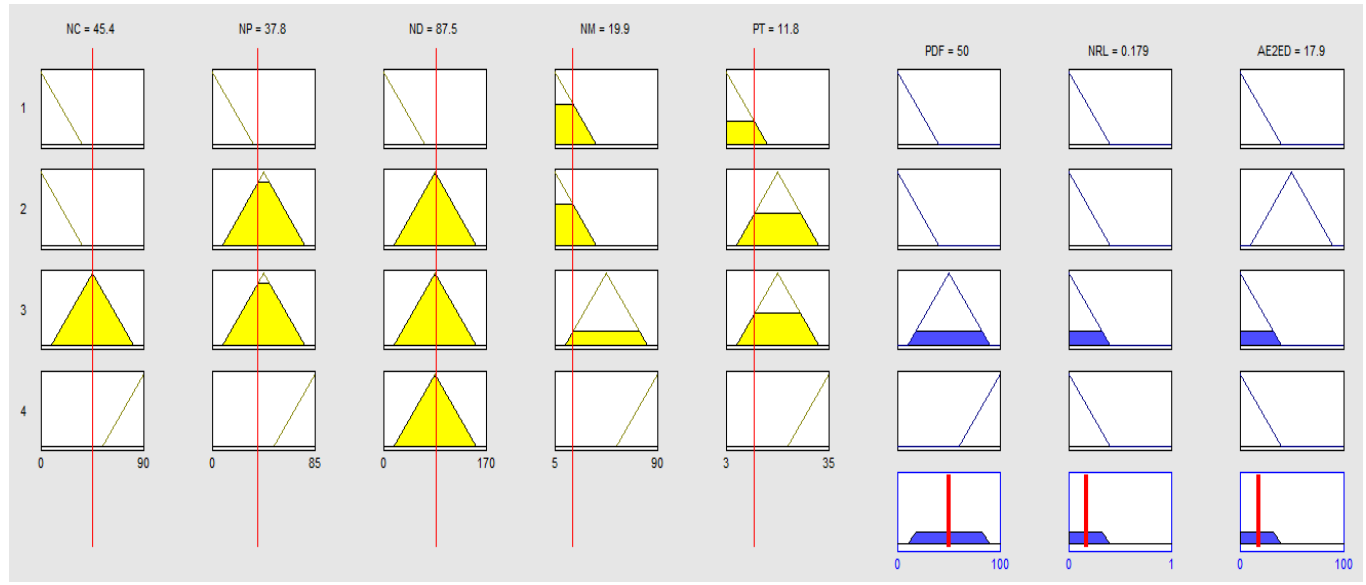

Figure 5. Sample Crisp Output of Inference System after Tuning DSR

\section{OVERVIEW OF SIMULATION RESULTS}

The objective of the fuzzy Inference System is to reducing the overheads to decide that in which types of network conditions the protocol performs poor, satisfactory or acceptable, Figure 1 shows the basic Inference System for applying Fuzzy Rules, it is the road map for implementing the model, Figure 2 shows the strength of fuzzy rules, Figure 3 represents how the input metrics are strengthened by Fuzzy Inference System to relate the effect on output metrics. With the help of proposed model using Fuzzy Inference System and after tuning out the behavior, MANET environment will be able to improve the performance by using DSR, according to the model it is observed that which parameters are to be focused to increase the performance in terms of more packet delivery fraction with minimum routing load and delay, the fuzzy rules are described in 
Figure 4 , after applying the rules the behavior of MANET for DSR is satisfactory, sample crisp output is shown in Figure 5.

\section{CONCLUSION}

This paper proposes a fuzzy logic based decision as a scenario selection method. This facilitates the generation of effective results that shows the necessity for performing the appropriate model, in conjunction with this, MANET area research will be able to gain the advantages of the Fuzzy Inference system that provides some direction that how to target the challenges to achieve higher throughput at minimum cost and delay. By observing the model it can be found that which input parameters influences output parameters, It is concluded that either increasing the number of nodes or changing the speed of movement, it will degrade the performance of DSR protocol. By using the proposed model, if number of connection, number of packets, node density node mobility speed and pause time is increased with proper ratio then, performance of DSR can be enhanced, if performance of DSR is increased then MANET is able to have low signal loss, high energy nodes environment.

\section{Acknowledgement}

I would like to Thanks to Dr. A.K. Sinha for motivating and guiding me at every step in my work, I am also thankful to ABES Engineering college management for The financial assistance provided in the form of travelling allowance and registration..

\section{REFERENCES}

[1] E. M. Royer and S. B. Chai-Keong Toh, “A Review of Current Routing Protocols for Ad Hoc Mobile Wireless Networks”, IEEE Personal Communications, April 1999, pp 46-55.

[2] M. Abolhasan, T. Wysocki and E. Dutkiewicz, "A review of routing protocols for mobile ad hoc networks", http:// www.elsevier.com/locate/adhoc, Ad Hoc Networks 2, 2004, pp 1-22.

[3] J. Broch, D.A. Maltz, D. B. Johnson, Y-C. Hu, and J. Jetcheva. A performance comparison of Multihop wireless ad-hoc networking routing protocols. In Proceedings of the 4th International Conference on Mobile Computing and Networking (ACM MOBICOM '98), October 1998, pages 85-97.

[4] Charles Perkins, Elizabeth Royer, Samir Das, and Mahesh Marina. Performance of two on-demand Routing Protocols for Ad-hoc Networks. IEEE Personal Communications, February 2001, pages 1628.

[5] Yang Cheng Hung, Saleem Bhatti, \& Daryl Parker titled on "Tuning OLSR" in The 17th annual IEEE International Symposium on Personal, Indoor and Mobile Radio Communications (PIMRC ' 06)[4].

[6] Thomas Staub, Computer Science Project, titled "Performance Comparison of MANET routing Protocols in Ad-hoc and Hybrid Networks" Computer Networks and Distributed Systems (RVS), Institute of Computer Science and Applied Mathematics (IAM), University of Berne, Switzerland, in February 2004.[5]

[7] [RFC 2501] S. Corson, J. Macker. Mobile Ad hoc Networking (MANET): Routing Protocol Performance Issues and Evaluation Considerations, January 1999.

\section{Bibliography}

Pankaj Sharma receivedThe BCA degree from CCS University Meerut, in $2001 \mathrm{Msc}(\mathrm{IT})$ from SMU Karnataka in 2003, MCA from NU Bhilai in 2003, \& M.Tech.(CSE) from GBTU Lucknow in 2010. Since 2005 I am working at ABES Engineering college Ghaziabad as Senior Assistant Professor in Information Technology Department .

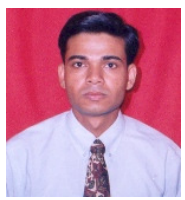

